\title{
Relatos de espacio: narraciones, movilidades y formas de habitar la metrópoli
}

\section{(4) Ramiro Segura}

CONICET/ Instituto de Altos Estudios Sociales, Universidad Nacional de San Martin / Laboratorio de Estudios en Cultura y Sociedad, Facultad de Trabajo Social, Universidad Nacional de La Plata, Argentina.

Orcid ID: orcid.org/oooo-0001-6482-3514

\author{
Mariana Chaves \\ CONICET / Laboratorio de Estudios en Cultura y Sociedad, Facultad de Trabajo Social y \\ Facultad de Ciencias Naturales y Museo, Universidad Nacional de La Plata / Centro de \\ Investigaciones en Políticas Sociales Urbanas, Universidad Nacional de Tres de Febrero, \\ Argentina. \\ Orcid ID: orcid.org/oooo-0oo1-8715-9468
}

Recibido: 3 de abril de 2019. Aceptado: 20 de septiembre de 2019.

\begin{abstract}
Resumen
El artículo presenta la estrategia metodológica desarrollada para el análisis antropológico de la experiencia metropolitana en el corredor sur de la Región Metropolitana de Buenos Aires. Se explicitan los criterios analíticos implementados para la definición del muestreo teórico que orientó el trabajo de campo; se precisa la construcción de tipos socio-urbanos para captar la heterogeneidad del espacio metropolitano; se especifican los criterios para la elaboración del protocolo de observación y la guía de entrevista; se muestra cómo se construyeron "relatos de espacio"; y finalmente se describen las operaciones analíticas realizadas con los datos producidos. El artículo se detiene especialmente a reflexionar sobre la productividad de los relatos para conocer las prácticas de espacio, las (in)movilidades y las resultantes (y diferenciales) formas de habitar la metrópoli. En este sentido, a la vez que reconoce la imposibilidad de los relatos para captar la multiplicidad de dimensiones involucradas en la movilidad entendida como práctica, sentido y experiencia, el artículo enfatiza en la cualidad de los relatos como viajes, producciones narrativas en las que se intersectan formas de hacer y formas de creer, informando simultáneamente sobre las prácticas en la metrópoli y las forma de significar la vida en metrópoli.
\end{abstract}

Palabras clave: Relato. Movilidad. Narrativa. Experiencia. Región Metropolitana de Buenos Aires. 


\title{
Stories of space: narrations, mobilities and ways of dwelling the metropolis
}

\begin{abstract}
The article presents the methodological strategy developed for the anthropological analysis of the metropolitan experience in the southern corridor of the Metropolitan Region of Buenos Aires. The article describes: the analytical criteria implemented for the definition of the theoretical sampling that guided the field work; the construction of socio-urban types to capture the heterogeneity of the metropolitan space; the criteria for the preparation of the observation protocol and the interview guide; the operations to build "space stories"; and the analytical operations carried out with the data produced. The article reflects specifically on the productivity of the "space stories" to know the practices of space, the (in) mobilities and the resulting (and differential) ways of dwelling the metropolis. In this sense, while recognizing the impossibility of "space stories" to capture the multiplicity of dimensions involved in mobility understood as practice, meaning and experience, the article emphasizes the quality of stories as trips, narrative productions in which intersecting ways of doing and ways of believing, simultaneously informing about the practices in the metropolis and the way of meaning life in metropolis.
\end{abstract}

Keywords: Story. Mobility. Narrative. Experience. Metropolitan Region of Buenos Aires.

Palavras-chave: História. Mobilidade. Narrativa. Experiência. Região Metropolitana de Buenos Aires.

"No hay viaje sin narración"

Ricardo Piglia

\section{Introducción}

En este artículo describimos y reflexionamos sobre la estrategia metodológica construida para desarrollar una investigación acerca de la "experiencia metropolitana" en el corredor sur de la Región Metropolitana de Buenos Aires (en adelante, RMBA). La pregunta por la experiencia metropolitana y, más concretamente, por la movilidad cotidiana en el espacio metropolitano que organizó dicha investigación, fue producto de un conjunto de investigaciones previas sobre segregación socio-espacial en sectores populares (Segura, 2015) y sobre circuitos urbanos juveniles (Chaves y Segura, 2015) que mostraron la imposibilidad de circunscribir la experiencia social de diversos actores (habitantes de barrios populares en el primer caso, jóvenes de clase media y de sectores populares en segundo), a determinados lugares de la ciudad (barrios en un caso, esquinas, instituciones y/o espacios de ocio en el otro). Estas investigaciones dieron cuenta que la vida urbana -con sus diferencias y sus desigualdades- no transcurre en lugares sino entre ellos (Ingold, 2011), impulsándonos a proponer la escala metropolitana como terreno de indagación en tanto contiene multiplicidad de formas y condiciones de vida, y a la movilidad como enfoque de la investigación (Zunino et al., 2018). En ese sentido, para nuestra investigación la movilidad constituyó una vía de acceso a la comprensión de las diversas y desiguales experiencias de la metrópoli.

Al momento de iniciar la pesquisa, el conocimiento acumulado sobre estas cuestiones podía ser agrupado en dos líneas de investigación consolidadas en el campo de los estudios urbanos locales. Por un lado, aquellas investigaciones acerca de la evolución 
socio-territorial de la región metropolitana, la cual para algunos analistas en las últimas décadas supuso el reemplazo del tradicional patrón de segregación residencial de gran escala (centro y periferia, norte y sur) por una fragmentación urbana que permitía la coexistencia en escalas reducidas de segmentos sociales heterogéneos y desiguales (Prévot-Schapira, 2001; Janoschka, 2002). Por otro lado, aquellas investigaciones de corte etnográfico y/o cualitativo que toman al "Gran Buenos Aires" o al "Conurbano" como escenario para estudiar procesos sociales a escala barrial, tendiendo a focalizarse en los extremos opuestos del universo metropolitano: los estudios centrados en villas, asentamientos y periferias (Cravino, 2008; Auyero y Swistun, 2008; Ferraudi Curto, 2014); y los estudios de las formas de habitar y los estilos de vida de los residentes de las urbanizaciones periféricas de sectores medios y altos (Svampa, 2004; Thuillier, 2005; Arizaga, 2005).

A partir del diálogo con estas dos líneas, nuestra investigación trató de comprender la dimensión metropolitana desde el punto de vista de la experiencia cotidiana (necesariamente plural y desigual) de sus residentes. De esta manera, mientras que con la primera línea de investigación compartió la escala de observación (lo metropolitano), con la segunda compartió el enfoque (etnográfico). A la vez, buscó introducir dos cuestiones de "relativa" vacancia: por un lado se trató de un abordaje antropológico que no se limitó a las figuras prototípicas y contrapuestas de la "villa" y el "country", sino que incorporó la experiencia de habitantes de otros espacios residenciales; por otro, tampoco se circunscribió a la indagación de los espacios barriales, sino que se abordó la movilidad cotidiana en tanto práctica constitutiva de la experiencia metropolitana. En este sentido, la pregunta por la movilidad cotidiana de habitantes de distintos y desiguales espacios residenciales buscó repensar los modos, muchas veces fijos y estáticos, de imaginar, representar y comprender la vida urbana. La pregunta por los desplazamientos no buscaba contraponer teorías "sedentaristas" de la vida social con metáforas "nomádicas" o "líquidas", sino analizar cómo se articulan y combinan las posiciones, las distancias y los desplazamientos en la vida urbana (Sheller y Urry, 2006), ya que entre la "inmovilidad forzada" y las diversas formas de "movilidad obligada" (Urry, 2002) se despliegan en la metrópoli diversas formas de movilidad cotidiana.

Además de describir la estrategia metodológica desarrollada para abordar estas cuestiones (muestreo teórico, tipos socio-urbanos, entrevista, observación, relatos, análisis), en este artículo se reflexiona especialmente sobre la productividad de los "relatos de espacio" (De Certeau, 2000) como vía para conocer las prácticas espacio-temporales, las (in)movilidades cotidianas y las resultantes formas de habitar la metrópoli. Nuestra experiencia investigativa nos lleva a reconocer la imposibilidad de los relatos para captar la totalidad de dimensiones involucradas en la movilidad entendida como práctica, sentido y experiencia (Cresswell, 2008), pero enfatizamos en la cualidad de los relatos como viajes, producciones narrativas en las que se intersectan formas de hacer y formas de creer, informando simultáneamente sobre las prácticas en la metrópoli y las formas de significar la metrópoli.

\section{Relatos de espacio, vía de acceso al habitar en movimiento}

De acuerdo con Ingold (2011), mientras que construir es un verbo transitivo, habitar es uno intransitivo. Habitar no supone simplemente la ocupación de las estructuras ya construidas, sino que involucra la forma en que los habitantes producen y despliegan sus propias vidas. Se trata de un proceso abierto e inacabado de significación y uso del medio ambiente realizado en el tiempo a través de un "conjunto de prácticas y representaciones que permiten al sujeto colocarse dentro de un orden espacio-temporal y al 
mismo tiempo establecerlo" (Duhau y Giglia, 2008:22-24). Habitar, entonces, implica movimiento en el espacio-tiempo, no se desarrolla en un lugar, sino a lo largo de los caminos que llevan de un lugar a otro.

"Experiencia metropolitana" refiere aquí a los modos en que los actores practican y significan el espacio, el tiempo, el sí mismo y a los demás en un espacio singular por su escala y heterogeneidad: la metrópoli (Mongin, 2006; Bourdin, 2007). El concepto de "experiencia" siempre ha estado tensado entre posiciones dicotómicas: de un lado, "la experiencia (presente) se propone como el fundamento necesario (inmediato y auténtico) para todo el razonamiento y análisis (subsiguientes)". Del otro, la experiencia (pasada) "se ve como el producto de condiciones sociales, sistemas de creencia o sistemas fundamentales de percepción y, por lo tanto, no como material de las verdades sino como evidencia de condiciones o sistemas que por definición ella no puede explicar por sí misma" (Williams, 2000:140). Nuestro desafío consistió en intentar salir de la dicotomía entre la experiencia (presente) como fundamento y la experiencia (pasada) como producto. Así como no es factible pensar la experiencia como el encuentro prístino entre sujeto y realidad, creencia que desconoce las mediaciones socioculturales en los modos de acercarnos a la realidad y supone el acceso a la "vivencia" en estado puro; tampoco se puede reducir la experiencia a un epifenómeno de las condiciones sociales e históricas, borrando las agencias sociales activas en la vida social. Experiencia remite en nuestro trabajo - $y$ en este texto- a los modos (eventualmente diferenciales) de ver, hacer y sentir (en nuestro caso, la metrópoli y la vida en la metrópoli) por parte de actores situados social y espacialmente, por el modo en que en sus vidas cotidianas -siguiendo a Williams (1997)- se vinculan lo que está socialmente articulado y lo biográficamente vivido (Segura, 2015).

Entonces, ¿Cómo conocer la experiencia metropolitana? ¿Cómo desplegar un abordaje antropológico de la metrópoli que siguiendo a los actores, sus prácticas, escalas espaciales y temporales y sentidos, no se circunscriba al locus habitual de los abordajes antropológicos (como el barrio)? ¿Cómo acceder a los movimientos por el espacio metropolitano y a la experiencia de ese movimiento?

Existe una multiplicidad de métodos que buscan captar las movilidades implicadas en el habitar cotidiano, cada uno de los cuales supone "ganancias" y "pérdidas" en lo que refiere tanto a los recursos y capacidades necesarias para implementarlos como al tipo de dato producido y a lo que esos datos permiten decir sobre la experiencia del habitar. Estas herramientas metodológicas van desde las tradicionales encuestas origen-destino hasta la proliferación de "métodos móviles", muchos de los cuales -como el "sombreo" (Jirón, 2010)- buscan moverse, estar y sentir junto a los sujetos y los objetos investigados (Merriman, 2013). Respecto de estos últimos métodos se ha matizado, sin embargo, la cuestión del movimiento, señalando que es importante no confundir "las movilidades" como objeto de investigación con "la movilidad" como metodología de investigación, ya que estos métodos no son "móviles" solo porque sirvan para recoger datos sobre el movimiento sino porque ayudan a comprender las diversas manifestaciones de las movilidades (Büscher y Veloso, 2018).

Entre todos ellos nos inclinamos por el relato, principalmente porque el relato, la experiencia y el viaje constituyen una tríada de categorías íntimamente ligadas. Por un lado, al menos desde trabajos seminales como "El narrador" de Walter Benjamin (1986), se ha señalado la conexión entre experiencia y narración: el relato como un

1 En el caso de la investigación en Argentina, como producto de un taller entre equipos de investigación sobre movilidades, recientemente se produjo un libro colectivo en el que se sopesan las virtudes, los costos y los límites de diversas metodologías (Gutiérrez, 2017). 
registro fundamental de la experiencia social, como la historia de un sujeto que se piensa y se construye a sí mismo a través del relato, que moviliza (y a veces desestabiliza) las categorías socialmente disponibles para narrar su vida, producto de la comparación incesante entre lo articulado y lo vivido. Por otro lado, un relato es un viaje de escalas temporales y espaciales variables (el relato de un día, el relato de una vida, el relato de una comunidad, etc.). Como sostuvo Michel de Certeau (2000) todo relato "es un relato de viaje, una práctica del espacio", donde "estas aventuras narradas, que de una sola vez producen geografías de acciones y derivan hacia los lugares comunes de un orden". Los relatos "cada día, atraviesan y organizan lugares; los seleccionan y los reúnen al mismo tiempo; hacen con ellos frases e itinerarios. Son recorridos de espacios" (2000:127-128).

De esta manera, los relatos se constituyen de descripciones de lugares, narraciones de vivienda o historias de la calle, en los cuales se combinan de maneras cambiantes descripciones de tipo mapa, donde predominan el "hay" y el "ver", y descripciones de tipo recorrido, donde prevalece el "ir" y "el hacer" (de Certeau, 2000:132), trasladándonos constantemente entre el lugar (orden sincrónico) y el espacio (o lugar practicado). La disponibilidad de relatos permitiría analizar el modo en que los habitantes de la metrópoli describen espacios, tiempos, actores y prácticas; cómo los ordenan, jerarquizan y vinculan; cuáles espacios permanecen intransitados e invisibles, en qué momentos, con qué significaciones y actores se vinculan; qué emociones despiertan esas prácticas, cuáles cambios identifican y qué sentido les otorgan. En definitiva, nuestra hipótesis es que los relatos constituyen una vía de acceso a la experiencia social de la metrópoli. Como bellamente escribió Ricardo Piglia en su ensayo Modos de narrar:

Si por uno de esos mecanismos [ficcionales] simples pudiéramos tener a nuestra disposición todos los relatos que circulan en una ciudad en un día; si yo tuviera la posibilidad de conocer todos los relatos que circulan en Buenos Aires o en Talca en un día, sabría mucho más sobre la realidad de ese lugar que todos los informes científicos y periodísticos y todas las estadísticas y todos los discursos de los economistas o de los sociólogos. Tendría en la multitud de historias que circulan en un día en un lugar, sin duda, una percepción muy nítida de la vida cotidiana de ese lugar, de la vida íntima de ese lugar, y eso no sería solamente una cuestión de contenidos de esas historias, no se trataría solamente de lo que se está contando sino de la forma con la que se lo está contando, el modo específico y preciso de usar la tradición del relato (2014:244).

Sin renunciar a los informes científicos ni a las estadísticas que también fueron revisados, nuestra investigación encontró en los relatos una vía de acceso a la experiencia metropolitana: el relato es un viaje que repone una experiencia, tanto por su contenido como por su forma. El problema estriba, por supuesto, en que no disponemos de alguno de esos mecanismos ficcionales simples por los cuales acceder a todos los relatos que circulan en un día en el espacio metropolitano. Por ello nos dimos la tarea de construir un dispositivo para acceder y producir relatos. En la siguiente sección lo describiremos en el marco de la estrategia metodológica general y de los criterios establecidos para la conformación de la muestra.

\section{Corredor Sur, tipos socio-urbanos y muestreo teórico}

La RMBA constituye un conglomerado metropolitano resultado de sucesivos ciclos de urbanización, industrialización, migración y conurbanización donde habitan alrededor de catorce millones de personas (un tercio de la población del país). Dos sistemas espaciales sobrepuestos estructuran a gran escala el espacio metropolitano: un sistema de anillos concéntricos y el eje cardinal norte-sur (Grimson, 2009). En 
términos de anillos (también llamados cordones o coronas) la RMBA incluye las siguientes jurisdicciones: a) Ciudad Autónoma de Buenos Aires (CABA), con una población de 3.100.000 de habitantes; b) Gran Buenos Aires ( $1^{\text {a }}$ y $2^{\text {a }}$ corona del conurbano), conformada por 25 partidos y una población que ronda los 9.000 .000 de habitantes; y c) el resto de la RMBA o " 3 a corona", compuesta por 15 partidos y una población que ronda los 1.700 .000 habitantes (Ciccolella, 2011). En este sistema concéntrico las condiciones socioeconómicas decrecen a medida que nos alejamos de la Ciudad Autónoma de Buenos Aires, con la excepción del tercer anillo que en las últimas dos décadas fue el escenario privilegiado de la expansión de las urbanizaciones privadas de clases altas sobre suelos de bajo costo, dando lugar a la coexistencia de fuertes contrastes sociales. Sobre este sistema concéntrico se sobreimprime el eje cardinal norte-sur, contraponiendo también a gran escala el sur como "tradicional y pobre" frente al norte "modernizado y próspero". Al este limita con el Río de la Plata y hacia el oeste emerge una situación intermedia y heterogénea. Se trata de tres brazos de urbanización (norte, oeste y sur) organizados inicialmente a finales del siglo XIX por el ferrocarril, con una gradación en la capacidad económica de norte a sur que a grandes rasgos persiste hasta hoy. A su vez, a una escala de observación más reducida es posible entender los ejes cardinales (norte, oeste y sur) de la RMBA como una estructura piramidal policéntrica, con centros suburbanos conectados funcional y simbólicamente con la CABA, y en torno de cada uno de los cuales se desarrollan anillos subperiféricos, que en general van disminuyendo la capacidad socioeconómica a medida que se alejan de cada subcentro (Gorelik, 2011).

Teniendo esta realidad urbana como escenario mayor -y frente a la imposibilidad de abarcarla- la investigación propuso conocer la "experiencia metropolitana" de los habitantes del "corredor sur" de la RMBA. Este corredor consiste en un eje de movilidad urbana conformado por algunas líneas del ferrocarril Roca, la autopista Buenos Aires-La Plata y las avenidas Calchaquí, Belgrano y Centenario como vías principales. El mismo corta transversalmente el sistema de anillos concéntricos y conecta hacia el sur a la Ciudad Autónoma de Buenos Aires con los partidos del primer, segundo y tercer cordón del conurbano metropolitano, atravesando los partidos de Avellaneda, Quilmes, Florencio Varela, Berazategui y la región Gran La Plata en el otro extremo (partidos de La Plata, Berisso y Ensenada). En este sentido, vale señalar que la idea de "corredor sur" operó en la investigación como un criterio de "recorte" geográfico dentro de la RMBA antes que como "objeto" de conocimiento. La motivación principal no consistió, entonces, en conocer las dinámicas de movilidad urbana del corredor (aunque indudablemente brindó indicios sobre estas dinámicas), sino que en cambio la idea de corredor permitió seleccionar un conjunto de localidades para indagar en la "experiencia metropolitana" de sus desiguales habitantes desde el "enfoque" de la movilidad. Este recorte, además, permitió agrupar localidades de distintos anillos que -con la excepción de La Plata- comparten ser producto del proceso de la expansión urbana e industrial hacia el sur del conurbano bonaerense que se cierra a mediados de la década de 1970 así como de una posterior serie de ciclos políticos de acción colectiva -paradigmáticamente, los asentamientos- que transforman "al sur" en un lugar distintivo (Pinedo, 2018). 


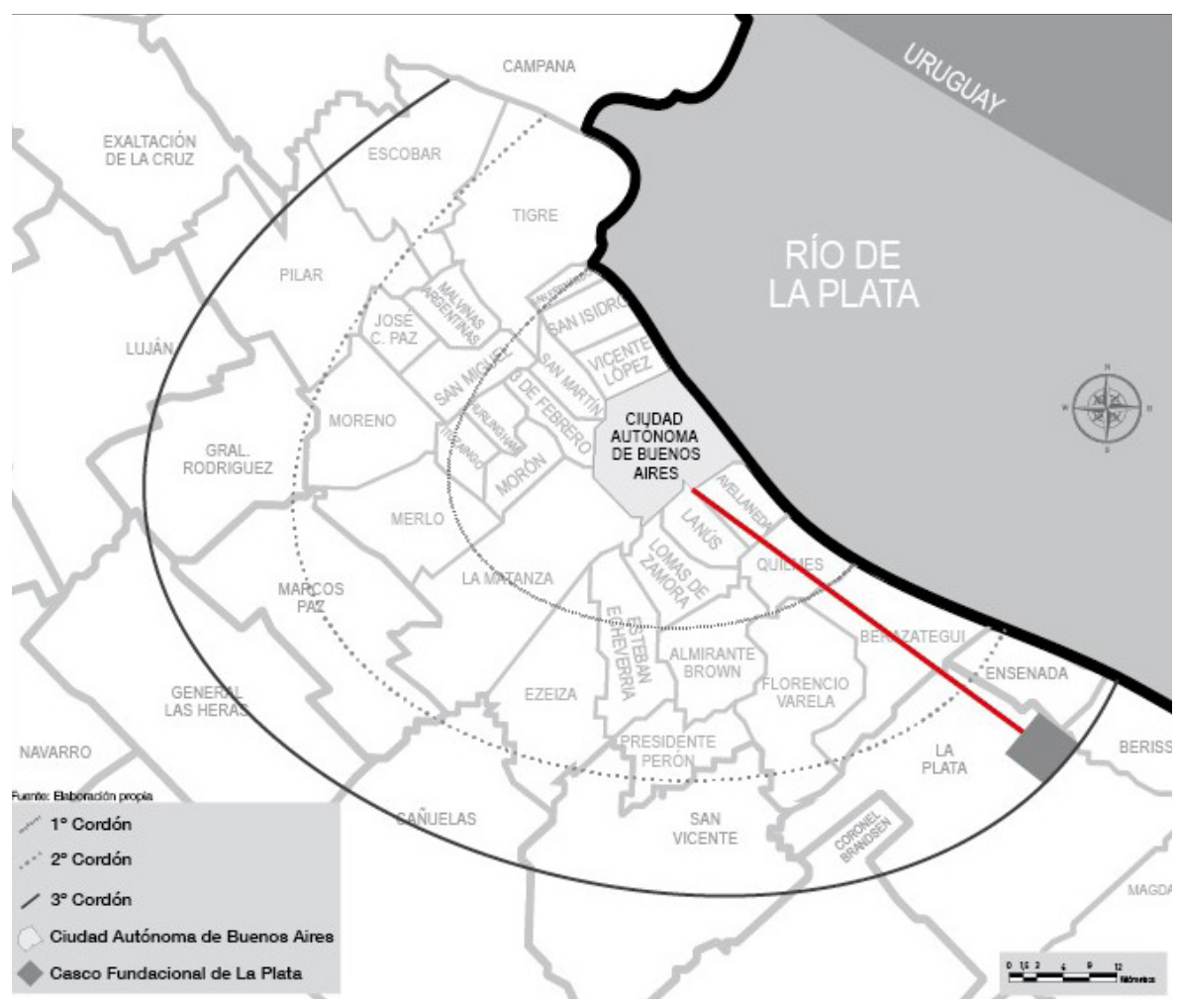

Figura 1. Región Metropolitana de Buenos Aires y su “corredor sur”. Fuente: elaboración propia.

Desde esa caracterización de la región nos abocamos a la construcción de un muestro teórico en base a tipos socio-urbanos que nos permitiera llevar adelante un abordaje antropológico de la "experiencia metropolitana" de las y los habitantes del "corredor sur". Para ello en primer lugar tuvimos en cuenta las estrategias desplegadas en investigaciones de otras grandes ciudades latinoamericanas, donde se plantea la necesidad de construir "puertas de acceso" que permitan ponderar fuentes de variabilidad en la experiencia metropolitana como la clase, la localización, el tipo de barrio, etc. Entre las investigaciones revisadas destacamos el trabajo ya clásico de Teresa Caldeira (2000) sobre inseguridad y miedo en Sao Pablo, que concentró su investigación en tres áreas al interior del espacio metropolitano, cada una de las cuales se correspondía a clases sociales; la investigación sobre movilidad cotidiana en Santiago de Chile desarrollada por Paola Jirón $(2007,2009)$ que organizó el espacio metropolitano en áreas concéntricas diferenciadas por su localización y su distancia respecto del centro; y la investigación colectiva dirigida por Emilio Duhau y Ángela Giglia (2008) en la Ciudad de México que construyó distintos tipos de "ciudades" que se diferenciaban fundamentalmente por la forma de producción del espacio urbano.

Recuperando esos trabajos previos y con el objetivo de acceder a la pluralidad y la desigualdad de experiencias que coexisten en el espacio metropolitano, se construyeron seis "tipos socio-urbanos" teniendo en cuenta la diversidad de situaciones económicas, sociales y espaciales de la RMBA y combinando los criterios desplegados en los trabajos mencionados (clase, localización y forma de producción del espacio). El resultado fueron seis tipos socio-urbanos: barrio cerrado, barrio tradicional de clases altas, barrio de clase media en casco urbano consolidado, barrio industrial, barrio periurbano de clase media/baja y asentamiento o villa. Estos tipos socio-urbanos no se equiparan de manera directa con "clases sociales", aunque nos permiten aproximarnos a ellas. De esta manera, si seguimos los planteos de Benza (2016) que recupera el lugar de la división 
social de trabajo de los estudios clásicos para identificar a las clases sociales así como los hogares como unidad de análisis, los residentes entrevistados en los tipos sociourbanos "barrio cerrado" y "barrio tradicional" ingresarían por sus ocupaciones en las clases altas (empresarios, ejecutivos) o medias altas (pequeños empresarios, profesionales), los residentes en el tipo "barrio de clase media en casco urbano consolidado" se corresponderían bastante con el extenso mundo de las clases medias (profesionales, técnicos y jefes intermedios, trabajadores administrativos y trabajadores de comercio) y los residentes en los tipos "barrio industrial" (asalariados calificados, trabajadores de oficios), "barrio periurbano" (cuentapropistas, asalariados no calificados) y "villa/ asentamiento" (asalariados no calificados, trabajadores marginales, beneficiarios de planes) se corresponderían con los heterogéneos sectores populares.

La construcción de estos "tipos socio-urbanos" permitió reducir la multiplicidad de situaciones residenciales y fue un paso necesario para construir la muestra. Al respecto, procedimos a realizar un "muestreo teórico" que contempló tanto las localidades que integran el "corredor sur" de la RMBA como los "tipos socio-urbanos" elaborados, resultando como muestra el siguiente cuadro:

Cuadro 1. Muestreo teórico de localidades y tipos socio-urbanos. Fuente: elaboración propia.

\begin{tabular}{|c|c|c|c|c|c|c|c|}
\hline TIPO SOCIO-URBANO & LOCALIDAD & 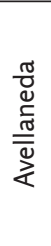 & $\frac{\mathscr{E}}{\bar{\Xi}}$ & 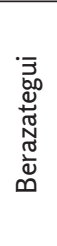 & $\begin{array}{l}\frac{\pi}{0} \\
\frac{2}{\pi} \\
\frac{0}{0} \\
. \frac{0}{U} \\
\frac{C}{0} \\
\frac{0}{4}\end{array}$ & $\begin{array}{l}\frac{\pi}{\pi} \\
\frac{\pi}{2} \\
\frac{\pi}{\square}\end{array}$ & 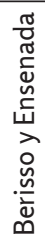 \\
\hline Barrio cerrado & & & & $\mathrm{x}$ & & $X$ & \\
\hline Barrio tradicional de clases altas & & & $\mathrm{x}$ & & & $\mathrm{X}$ & \\
\hline Barrio de clase media en casco urbano & & $x$ & & & $X$ & & \\
\hline Barrio industrial & & & & $X$ & & & $x$ \\
\hline Barrio periurbano de clase media/baja & & $x$ & & & & & $\mathrm{X}$ \\
\hline Asentamiento /villa & & & $\mathrm{X}$ & & $\mathrm{X}$ & & \\
\hline
\end{tabular}

Este muestreo se transformó en la hoja de ruta del desarrollo del trabajo de campo, donde $\mathrm{X}=10$ entrevistas, teniendo como objetivo el desarrollo de 20 entrevistas por tipo socio-urbano y 20 entrevistas por localidad (con la excepción de Berisso y Ensenada), totalizando 120 entrevistas (de las que finalmente se pudieron desarrollar 90).

\section{Trabajo de campo}

Todas las instancias del trabajo de campo fueron colectivas, participando en su desarrollo muchos investigadores/as que se encontraban en distintos momentos de formación académica, con nuestra orientación. ${ }^{2}$ Por este motivo el trabajo de campo exigió la construcción de herramientas de observación, descripción y entrevista que explicitaran claramente las dimensiones a observar y describir y los ejes para entrevistar. También se realizaron instancias de capacitación para la implementación de las herramientas.

El campo se desplegó a diversas escalas. En primer lugar, el trabajo de campo supuso la descripción de cada uno de los municipios del corredor sur por medio del relevamiento, 
sistematización y análisis de fuentes primarias y secundarias. Esta descripción incluyó no solo sus características sociales y urbanas (historia, infraestructuras, servicios, instituciones, medios de transporte, actividad económica, etc.), sino también las "matrices políticas locales", ya que se habían mostrado relevantes en una investigación previa (Grimson y Segura, 2016). ${ }^{3}$ En segundo lugar, una vez seleccionadas las zonas que representarían los tipos socio-urbanos del muestreo teórico para cada localidad, por medio de la observación participante se buscó describir cada uno en tanto contexto relevante que compartirían los y las entrevistadas que residían en ellos. Esta actividad fue simultánea al abordaje de la tercera escala de investigación: la selección y realización de las entrevistas a las diez unidades domésticas ${ }^{4}$ en cada uno de las zonas seleccionadas.

Como decíamos, en cada uno de los barrios se realizaron diez entrevistas a personas mayores de 18 años, intentando mantener las proporciones por género y edad y, por lo mismo, evitar el habitual sesgo de entrevistar predominantemente a mujeres y/o adultos mayores que se produce al hacer entrevistas en la residencia. El muestreo teórico intencional constituyó, entonces, la guía para "saturar" la heterogeneidad de tipos socio-urbanos y de personas entrevistadas en cada uno de ellos, mientras que la técnica de la "bola de nieve" fue la estrategia para acercarnos a potenciales personas a entrevistar, a partir de conocidos/as que nos facilitaban contactos iniciales en cada uno de los tipos socio-urbanos y de personas entrevistadas que nos sugerían otras personas para entrevistar. Nunca el total de entrevistas por barrio se saturó por una sola red, lo que puede hablar de la sociabilidad en el espacio residencial. En cada barrio, en cambio, iniciamos diversas "bolas de nieve" para cumplir con la totalidad de las entrevistas, respetando las ya mencionadas proporciones de edad y género. Asimismo, a diferencia de investigaciones que para la constitución de la muestra se han centrado en personas con alta movilidad (Jirón, 2007) o personas con movilidades específicas hacia algún servicio (Gutiérrez, 2012), nosotros no supeditamos la selección de un entrevistado/a al tipo de movilidad cotidiana (su escala, su finalidad, etc.). Al contrario, las personas que cumplieran los requisitos para ser parte de la muestra (vivir en el barrio seleccionado, ser mayor de 18 años, respetar proporciones de edad y género de la muestra) y accedieran a brindarnos parte de su tiempo fueron entrevistadas, permitiéndonos a acceder a la multiplicidad y la heterogeneidad de prácticas de movilidad cotidiana en el espacio metropolitano.

Se trató de entrevistas semi-estructuradas, realizadas en la vivienda de el/la entrevistado/a, con una duración promedio de una hora, cuyo objetivo fue conocer las actividades que hacen todos los días los/as integrantes de la unidad doméstica, dónde se desplazan, cuándo, cómo, con quiénes y cómo significan esas prácticas. La propuesta de la "historia de viaje" (Gutiérrez, 2012 y 2017) constituyó, en este sentido, un antecedente relevante para el diseño de nuestra herramienta. Las diferencias en el objeto de conocimiento de ambas investigaciones explican en gran medida las disimilitudes entre ambas entrevistas: mientras la "historia de viaje" es una entrevista que busca conocer un viaje habitual para acceder a un servicio, nuestra "entrevista de vida cotidiana y movilidad" (Chaves y Segura, 2017) busca reconstruir la totalidad del día anterior a la entrevista de la unidad doméstica, ampliando la indagación en lo relativo al número de personas y al número de viajes.

3 En este sentido, por ejemplo, lo que podríamos Ilamar "tolerancia diferencial" del poder municipal hacia la instalación de asentamientos informales en dos municipios contiguos -Florencio Varela y Berazategui- permeó gran parte de la experiencia cotidiana de los habitantes de ambos lugares.

4 La "unidad doméstica" fue definida exclusivamente en términos de co-residencia, es decir, como un grupo de personas que comparte la vivienda, sin exigir que sus miembros compartan las comidas ni tengan necesariamente un presupuesto común. 
En términos estrictos, la entrevista no se iniciaba en el momento de llegar a la vivienda, sino cuando se tomaba contacto con la persona a entrevistar, sea por telefonía fija, celular, redes sociales o mail. A partir de las primeras entrevistas nos dimos cuenta que esa comunicación previa, además de establecer la cita, propiciaba una información relevante expresada en indicaciones y recomendaciones sobre cómo llegar al lugar donde se llevaron adelante la mayor parte de las entrevistas: la casa de la persona entrevistada. Esto nos permitía recabar una primera descripción por parte de la persona entrevistada, en sus comentarios sobre si era fácil o difícil llegar, si estaba bien conectada o no, cuáles eran las opciones disponibles y aquellas que el/la entrevistado/a prefería, cuáles eran los riesgos, etc. Una vez en la casa, la entrevista buscaba conocer el día anterior en la vida cotidiana de cada uno de los miembros de la vivienda, comenzando por el/ la entrevistado/a y siguiendo luego con el resto de las y los integrantes de la unidad doméstica.

El diseño general de la entrevista apuntaba a que el eje del intercambio pasara por el relato que la persona realiza de un día habitual y de los fines de semana o día excepcional de su vida, para pasar luego a los relatos sobre las actividades y movimientos de las y los demás habitantes de la casa. La entrevista buscaba propiciar relatos formulando preguntas concisas pero abiertas, del tipo: “¿Cómo fue el día de ayer para vos?” y “¿Cómo es vivir acá?". Con ello se propiciaba que la persona entrevistada despliegue un relato -y se despliegue en el relato- de sus prácticas cotidianas y, por medio de ellas, establezca las coordenadas y las escalas espacio-temporales en las que se desarrolla su vida y la de las demás personas de la unidad doméstica. No había, por lo mismo, una serie fija y rígida de preguntas, pero sí unas dimensiones que la entrevista buscaba relevar y sobre las que era posible preguntar y repreguntar a medida que se desplegaba el relato. Para esto fue de utilidad instrumentar metodológicamente la propuesta teórica de cinco dominios urbanos del antropólogo sueco Ulf Hannerz (1986): doméstico, aprovisionamiento, vecindad, ocio y tránsito. Nos interesaba conocer la espacialidad y la temporalidad de las prácticas involucradas en cada uno de esos dominios, las formas en que se desplazaban o se superponían esos dominios, los senderos que los conectaban entre sí, los medios a través de los cuales se hacía el viaje entre los dominios y los sentidos de las personas acerca de esas experiencias de la movilidad en el espacio metropolitano.

\section{Codificación de entrevistas y construcción de relatos}

Las entrevistas fueron desgrabadas y transcriptas y se acompañaron con la descripción etnográfica de la vivienda, el barrio, el viaje llevado a cabo por el investigador y el relato de cómo acceder a la casa realizado por la persona entrevistada en el momento de contactarla.

El procesamiento de la información implicó el desarrollo de dos operaciones complementarias. Por un lado, la totalidad del material de las entrevistas (y las descripciones que las acompañaban) fue codificada con el soporte informático Altas Ti, combinando códigos preestablecidos y códigos emergentes de la lectura y análisis del material. Este trabajo de codificación también fue colectivo, tanto en lo relativo a la construcción y definición de las categorías como en lo referido a la tarea de codificar. Se construyeron 10 familias de códigos que se aplicaron a la totalidad de las entrevistas:

1) “dominios de actividad", con cinco códigos que replicaban la mencionada propuesta de Hannerz (1986);

2) "categorías socio-espaciales", compuesta por nombres propios - de países, ciudades, localidades, barrios-, categorías espaciales -periferia, suburbio, conurbano, pueblo,-., y artefactos urbanos que funcionaban como vías, límites, nodos e hitos;

3) "tiempos", compuesta tanto por códigos que referían al pasado, al presente y al futuro, momentos del día, de la semana y del año, y experiencias del tiempo; 
4) "sensaciones", con códigos como miedo, placer, temor, aburrimiento, etc.;

5) "movilidades", bajo el cual se incluyeron códigos relativos a medios de transporte, circuitos cotidianos, actividades en movimiento, saberes involucrados en la movilidad y arreglos para moverse;

6) "alteridades" codificaba nominaciones sobre "otros";

7) "problemas", que codificaba lo que las y los entrevistados nominaban como problemáticas;

8) "gustos", que codificaba gustos y disgustos de la experiencia metropolitana;

9) "interacciones", que codificaba las relaciones establecidas en la movilidad por el espacio metropolitano; $y$

10) el par "seguridad/inseguridad", compuesta por los códigos sensación de seguridad, sensación de inseguridad, arreglos por situación de inseguridad y evaluaciones comparativas de situaciones de inseguridad.

A cada una de las personas que participaron en la codificación se le dio una familia de códigos que aplicaron a la totalidad de las entrevistas, lo que permitía que una misma cita (fragmento de entrevista) sea codificada por más de un código, así como que la lectura del mismo material por muchas personas enriqueciera el sistema de códigos al identificar la necesidad de crear un nuevo código o de unir dos. Una vez finalizada la tarea, pudimos hacer una lectura "transversal" de las entrevistas, identificando convergencias y divergencias por localidad, tipo socio-urbano, clase, género y edad respecto de cada uno de los códigos. ¿Hay variaciones en los viajes y sus sentidos por localidad? ¿Y por tipo socio-urbano? ¿Los malestares de la vida urbana son los mismos según localidad, barrio, género o edad? ¿Cuáles son sus diferencias? Estas y muchas otras preguntas se le formularon a este material.

Por otro lado, de manera simultánea a la lectura transversal de las entrevistas, se tornó evidente que había que mantener unificada cada una de las experiencias individuales relevadas, para captar las dinámicas cotidianas de el/la entrevistado/a, las interdependencias con otros miembros de la unidad doméstica y con los condicionamientos del lugar de residencia, las valoraciones de los lugares por los que transitaba cotidiana o excepcionalmente, y las interacciones con los actores con los que se encontraba en esos tránsitos. Por este motivo, además de la codificación de cada una de las entrevistas se produjeron "relatos de espacio", basados en las entrevistas, la observación etnográfica y la información documental y cartográfica disponible. Siendo el centro de este artículo los relatos, transcribiremos a continuación un ejemplo, basado en una entrevista realizada a una joven que residía junto a su familia en un barrio industrial de la localidad de Ensenada, en el Gran La Plata:

Laura tiene 21 años y desde hace 10 años vive junto a sus padres y su hermano menor en el barrio COVEN (Cooperativa de Vivienda de Ensenada), una cooperativa de viviendas de los empleados de Astillero Río Santiago. Su padre, de 48 años, trabaja en Astilleros y su madre, de 47 años, es directora en un jardín de infantes en La Plata. Mientras su hermano, de 18 años, está finalizando la tecnicatura en astilleros, Laura estudia el último año de la licenciatura en nutrición en una universidad privada de la ciudad de La Plata.

La dinámica cotidiana de la familia se estructura en torno de dos actividades fundamentales: el trabajo y el estudio. En la casa cuentan con un vehículo que utiliza principalmente la madre, ya que diariamente viaja desde COVEN hasta La 
Plata (30 minutos), ya sea al Jardín de Infantes ubicado en 22 y 75 donde es directora como al Colegio localizado en 15 entre 76 y 77, donde es tesorera. La conjunción de ambas tareas hace que el retorno a la casa dependa del momento del mes y de la dinámica de las escuelas. Su padre, en cambio, trabaja en Astilleros entre las 7 de la mañana y las 3 de la tarde. Por la mañana va al trabajo caminando (45 minutos); por la tarde regresa con un compañero que lo acerca hasta el camino Rivadavia y luego camina el trayecto restante (10 minutos). Al regresar del trabajo tanto la madre como el padre se quedan en la casa. "No son de salir para nada -cuenta Laura-. Salen porque tienen que salir a trabajar, pero después son re caseros".

El hermano de Laura va entre las 7 y las 13 horas al colegio con un compañero en auto o lo lleva la madre y siempre regresa en micro. Después duerme la siesta y por la tarde va algunos días a la Universidad Tecnológica Nacional donde comenzó a estudiar ingeniería (en el secundario está realizando el año extra para obtener la tecnicatura). Por su parte, Laura pasa gran parte de la mañana en su casa (con la excepción de dos veces por semana que va a pilates), cocina y almuerza sola (su padre y su hermano almuerzan en Astilleros, su madre en La Plata) y a las cuatro de la tarde sale en micro para la facultad en La Plata (44 entre 9 y 10). Generalmente camina 10 minutos hasta el Camino Rivadavia y ahí se toma el colectivo 307 que la deja en Plaza Italia. Prefiere hacer esto porque el 307 es más rápido que el $275 \mathrm{y}$, además, este último la deja en 7 y 51 , debiendo luego caminar varias cuadras hasta la facultad. El medio utilizado para regresar depende de la hora de salida. "Si salgo a las diez, muy tarde, me van a buscar". En cambio, si sale más temprano regresa en el 307 y se baja en el camino Rivadavia. Ahí la van a buscar en auto "porque todo eso no me lo camino de noche". De manera similar, los fines de semana que sale de noche en La Plata, la llevan en auto y "después para volver me voy a dormir a lo de alguna amiga que vive en La Plata”.

Respecto de sus viajes, Laura reconoce que el motivo fundamental es el estudio. Mientras de ida "me duermo en el viaje, más si me levanté temprano", en el viaje de vuelta no duerme y "si tengo que estudiar me pongo a leer". El problema, sin embargo, es conseguir asiento. "Por ahí en el 275 sí [se consigue], pero en el 307 [la opción preferida] para la facultad a la tarde, normalmente no se consigue. Siempre se baja mucha gente en la estación de tren y ahí las pocas cuadras que quedan me siento, pero normalmente hasta ahí voy siempre parada". Sin embargo, ante la pregunta por la posibilidad de ir en auto, ella responde negativamente. "Una sola vez fui en auto y no lo podés estacionar, no hay lugar, no, es imposible (...). Prefiero el micro. Que se ocupe el chofer del quilombo de los autos. Yo voy durmiendo (se ríe)".

Esta preferencia implica ajustar su rutina a los tiempos del transporte público: "si entro a las seis o en alguna hora en punto, lo que tendría que hacer, que no lo hago mucho y siempre se me hace tarde, y cuarto tendría que salir de acá, para y treinta y cuatro, creo que pasa un micro, y tomármelo para ir con tiempo". Ese micro la deja menos cinco en Plaza Italia, lo que supone un tiempo total de 40 minutos entre caminata y colectivo. En este sentido, le gustaría que el 275 (que es el que pasa más cerca de su barrio) "pase más seguido".

A Laura le "encanta" vivir en Ensenada, a la que describe como "medio pueblo" y contrasta con La Plata. Reconoce que "ahora estoy más acostumbrada" pero cuando estaba en el colegio en Ensenada cada vez que "iba al centro" volvía con dolor de cabeza. La tranquilidad del lugar donde vive constituye una de sus ventajas, mientras que entre las dificultades señala que "hay cosas que tenés que ir a hacer a La Plata, por ejemplo ir a la facultad, o trámites e ir al médico". Las compras, en cambio, las hacen en Ensenada aunque "por ahí [sus padres] van a Nini [un supermercado 
mayorista localizado en Ringulet] cada tanto". Más allá de estos desplazamientos entre el "barrio" y "La Plata" o "el centro", la vida cotidiana de Laura y su hermano implican otras movilidades (al club, a pilates, a ver amigos y parejas, entre otros) dentro de Ensenada que, dependiendo del clima, realizan en bicicleta.

El encuentro diario de los miembros de la familia se produce fundamentalmente en la cena. Mientras almuerzan por separado, cenan juntos. Laura señala: "siempre cocina mi mamá".

En el ejercicio de construir el relato de viaje se trata de sistematizar los datos existentes produciendo un texto donde se pueda leer la constitución de la unidad doméstica, el tipo de barrio que se habita y las dimensiones de la entrevista ya descriptas. La producción del texto está en manos del investigador, se trata de una re-organización de un texto en formato desgrabación a un texto de narración continua, organizada siguiendo una secuencia temporal, con selección de información y énfasis en los términos nativos que significan la experiencia urbana. Esos textos son los relatos con los que trabajamos. Por ejemplo de la lectura de éste en particular se desprenden diversas cuestiones: el rol del trabajo (en el caso del padre y la madre) y el estudio (en el caso de Laura y su hermano) en las dinámicas cotidianas de la unidad doméstica; la centralidad de la empresa Astilleros en la vida familiar (residen en viviendas construidas por una cooperativa de trabajadores) $\mathrm{y}$, especialmente, en las dinámicas cotidianas de los varones de la familia (trabajo en un caso, estudio en el otro); los saberes y la reflexividad involucrados en la elección que realiza Laura de los medios transporte: la preferencia del colectivo por sobre el auto para ir a La Plata, la elección de una línea sobre otra basada en consideraciones relativas a la frecuencia, la velocidad, el tipo de gente, el recorrido, etc., y el viaje como un espacio-tiempo donde se duerme o se estudia; los "arreglos" familiares involucrados en estas movilidades: el auto es de uso prioritario por parte de la madre, quien también se encarga de llevar a su hijo al colegio por la mañana, el padre o la madre van a buscar a Laura al regreso de la universidad (ya sea a La Plata o a la parada del colectivo en Ensenada); y la preocupación por los entornos y los momentos del día y de la semana en que Laura se mueve: los padres la van a buscar al regreso de la facultad y hay toda una organización relativa a las salidas nocturnas; entre otras cuestiones.

Como veremos en el siguiente apartado, la construcción y análisis de los relatos y su comparación permitió captar la heterogeneidad de experiencias que existen entre habitantes, así como ponderar el lugar de la clase, el género, la edad, el momento del curso de vida individual y familiar, la residencia, etc., en la producción y reproducción de esas diferencias y desigualdades en la experiencia metropolitana.

\section{Hacia un análisis de los relatos de espacio}

El análisis de los relatos se desplegó en distintas escalas (municipios, tipos sociourbanos, unidades domésticas) y en relación a diversos debates de los estudios urbanos contemporáneos (segregación, género, curso de vida). Además, como ya indicamos, el trabajo con los relatos dialogó con el material discusivo codificado y la contextualización producto del relevamiento, la observación y la descripción de los contextos municipales y barriales en los que se desarrolló el trabajo de campo. A lo largo de la investigación las distintas escalas y los diversos problemas dialogaron recíprocamente y enriquecieron la comprensión de las movilidades cotidianas en la experiencia metropolitana. Veremos sintéticamente algunos ejemplos de los análisis realizados. 


\section{Los relatos como herramienta para develar patrones de movilidad}

Una de las operaciones analíticas realizadas con los relatos consistió en el mapeo de los recorridos cotidianos. En efecto, en tanto el relato se estructura como un viaje, metafóricamente permite "seguir a los actores" en sus trayectos por el espacio metropolitano y comprender cómo a través de sus prácticas los actores producen la escala de su vida diaria -tal como se propone desde la sociología pragmática (Latour, 2008) y desde la etnografía multisituada (Marcus, 2001)-. Los siguientes dos mapas representan las movilidades cotidianas de las personas entrevistadas en Florencio Varela (Chaves et al., 2018), para los tipos socio-urbanos "barrio de clase media" (Figura 2) y "asentamiento" (Figura 3) respectivamente.

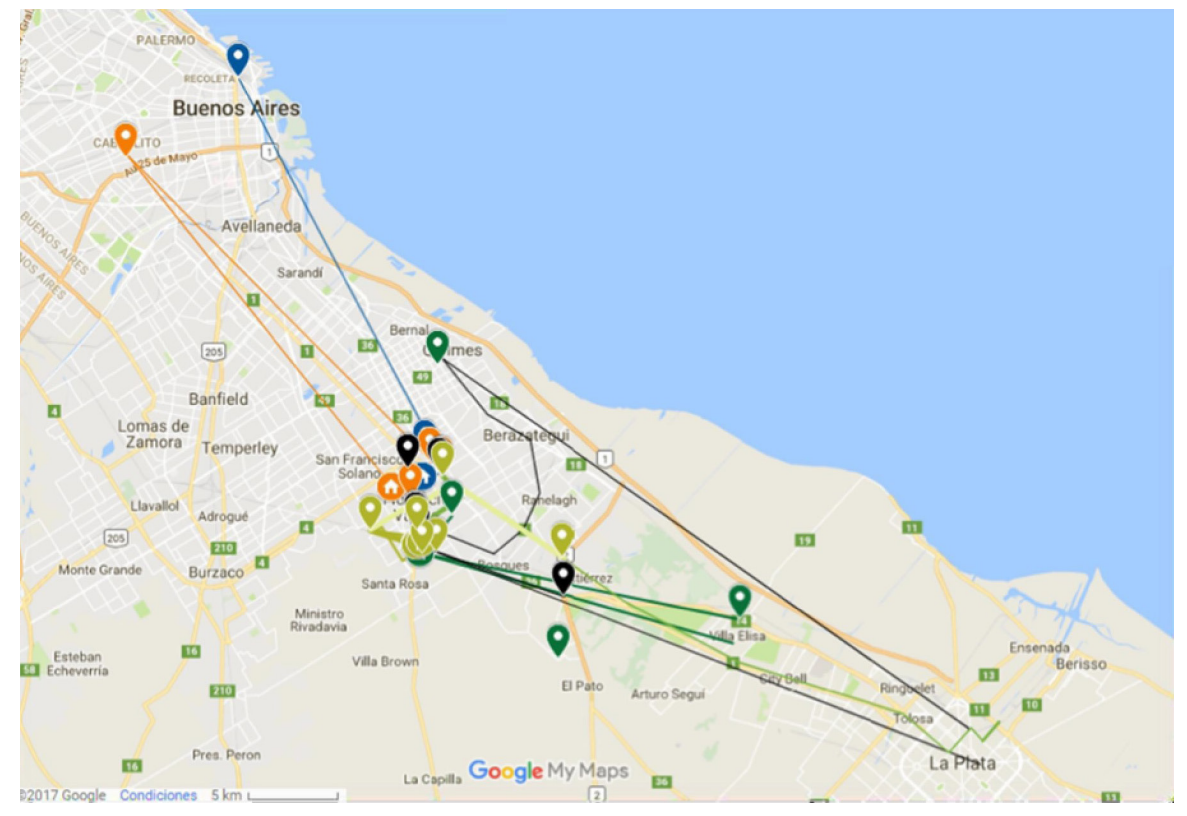

Figura 2. Movilidades cotidianas en Florencio Varela, clases medias. Fuente: elaboración propia.

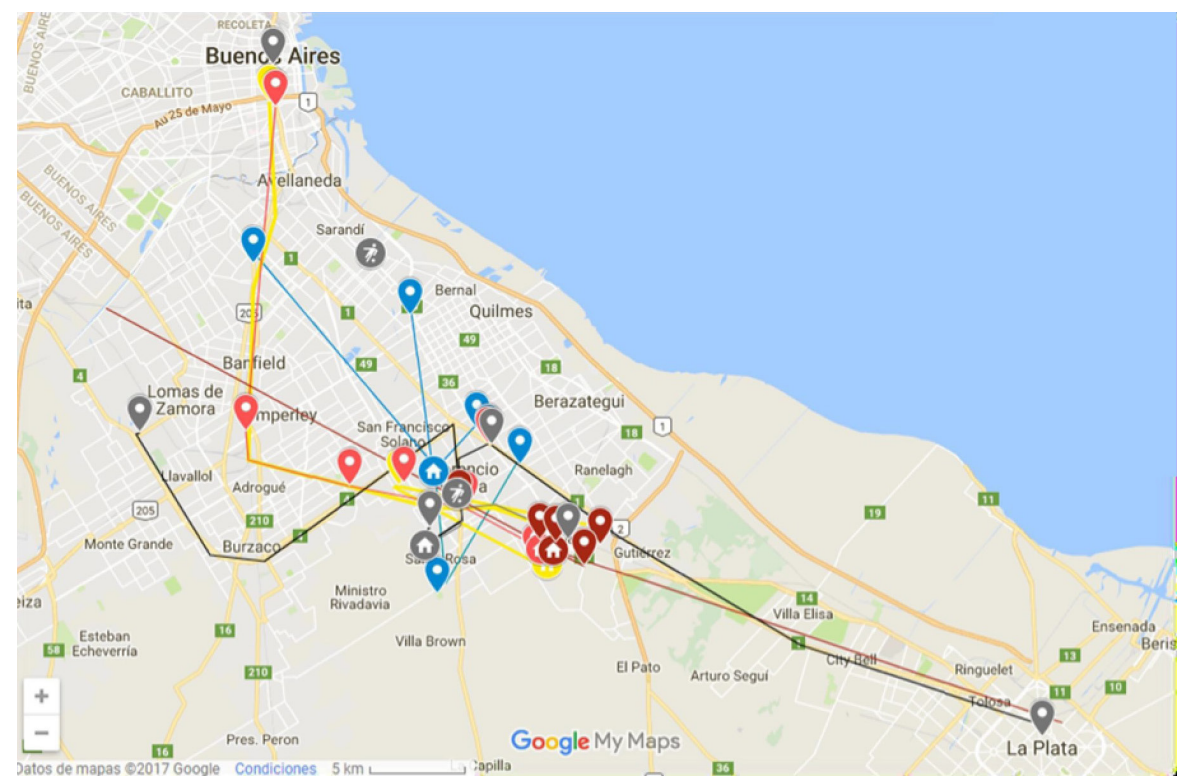

Figura 3. Movilidades cotidianas en Florencio Varela, asentamientos. Fuente: elaboración propia. 
De ambas cartografías puede llamar la atención la escala metropolitana de la movilidad cotidiana, ya que ésta no se circunscribe al barrio ni incluso al municipio. Esta movilidad metropolitana, además, no está orientada exclusiva o principalmente hacia Buenos Aires, sino que involucra también otros destinos relevantes como La Plata (por estudio en clases medias, por acceso a la salud en residentes del asentamiento) y municipios cercanos como Lomas de Zamora, Quilmes y Berazategui, teniendo a Bosques y al Cruce Varela como nodos clave de estos desplazamientos. En efecto, de las entrevistas con residentes de ambos tipos socio-urbanos se desprende que Florencio Varela es vivido por sus habitantes no solo como una "ciudad dormitorio" (ya que los puestos de trabajo se encuentran fuera de la localidad) sino también como un lugar mal conectado en términos de transporte y accesibilidad: una "ciudad dormitorio" que presenta grandes dificultades para movilizarse. Los relatos dan cuenta de trayectorias de viaje del tipo multimodales complejos, que combinan en algunos casos hasta tres medios de transporte para poder llegar a un destino que, en términos de distancias físicas, no está tan alejado como para justificar tales combinaciones y tiempos, pero así deben realizarse por la distribución y recorridos de los medios de transporte.

Esta tendencia "centrífuga" predominante en Florencio Varela (movilidades que se alejan de su centro), contrasta si la comparamos con los patrones de movilidad observados en La Plata (figura 4). Veamos el siguiente mapa, donde se representan las movilidades de los dos tipos socio-urbanos analizados en el proyecto en La Plata (barrio cerrado y barrio tradicional -llamado norte-), de un barrio industrial en Ensenada y de un barrio popular (Altos de San Lorenzo) producto de otra investigación (Segura, 2012): ${ }^{7}$

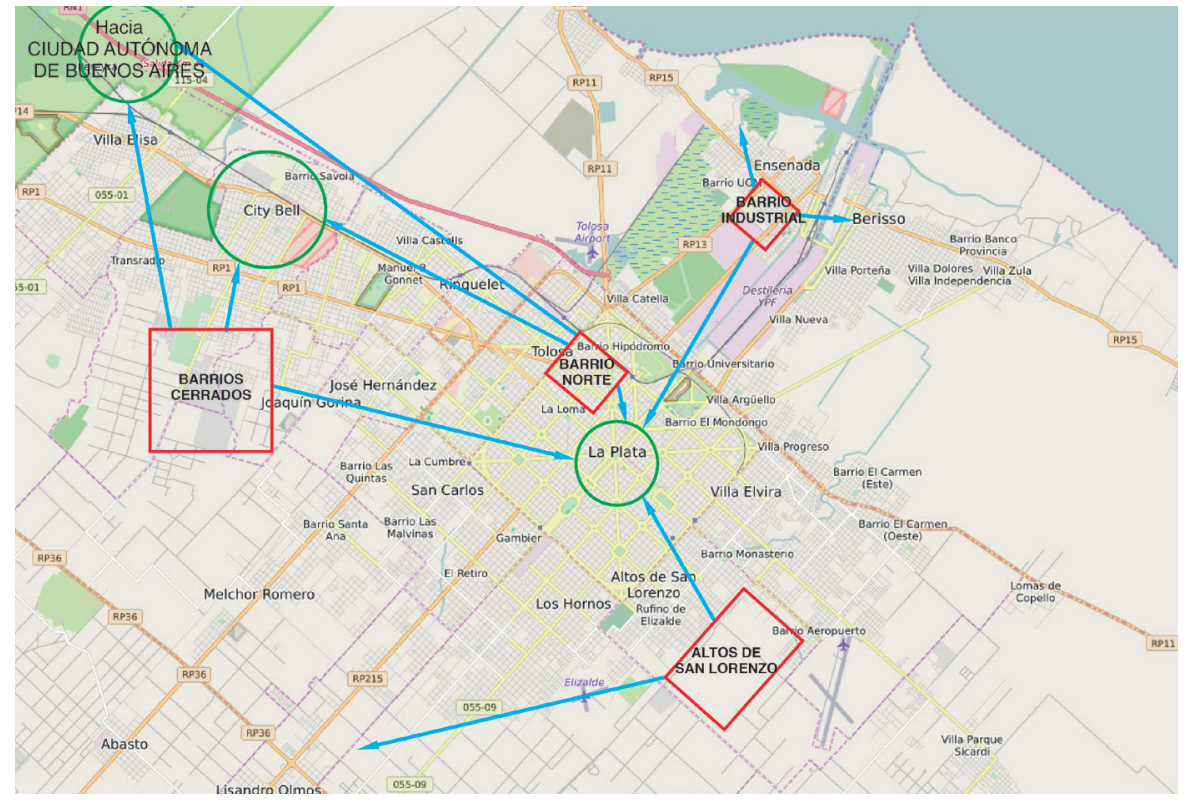

Figura 4. Movilidades cotidianas en La Plata. Fuente: elaboración propia.

En el mismo, si bien se observan movilidades cotidianas hacia Buenos Aires, estas se circunscriben a los sectores medios y altos (habitantes de los tipos socio-urbanos "barrio cerrado" y "barrio de clase alta tradicional") que a su vez han construido un 
nodo de consumo y sociabilidad en City Bell. Al mismo tiempo, resulta legible una tendencia "centrípeta": los trayectos de todos los habitantes confluyen en el centro de la ciudad o al menos tienen en ese espacio uno de los pocos nodos que comparten (Segura, 2018a).

\section{Modos de habitar y dinámicas de la segregación urbana}

Los relatos y las cartografías resultantes pueden ser analizados a escala municipal comparando, como sugerimos, patrones o lógicas de movilidad diferencial entre las localidades que integran la región metropolitana. Pero también la investigación permite analizar la relación entre "tipos socio-urbanos" y lo que denominamos "modos de habitar" (Segura, 2018 b; Segura y Chaves, 2019). Nos referimos a que la localización de la vivienda, la forma del espacio residencial, las condiciones socioeconómicas de las y los habitantes, la accesibilidad a los lugares de trabajo y a bienes y servicios como la educación, la salud, el tiempo libre y la disponibilidad de transporte, determinan modos específicos de habitar la ciudad. En un sentido similar, Duhau y Giglia (2008) formularon la hipótesis de la existencia de una correlación entre el tipo de espacio socialmente producido y la práctica de apropiación del espacio urbano en la Ciudad de México. Esto sería legible en las relaciones que las y los habitantes de los distintos espacios residenciales establecen con los tipos de vivienda, el entorno del barrio y el resto de la metrópolis, así como en sus estrategias diarias, sus predilecciones y sus mapas urbanos (reales e imaginarios). Por su parte Donzelot (2004) recurrió a la metáfora de "la ciudad de las tres velocidades" para referirse a la relación cambiante entre las formas espaciales, las condiciones socioeconómicas y las formas de vida: suburbios (alta movilidad y protección), relegados (inmovilidad e inseguridad) y gentrificación (ubicuidad).

En este sentido, para limitarnos a la última cartografía presentada (Figura 3), los relatos de los habitantes de un barrio tradicional central de La Plata, barrios cerrados de la localidad de City Bell en el eje Buenos Aires-La Plata y un asentamiento informal en la periferia mostraron regularidades en relación con las distancias, los tiempos, la movilidad y circuitos por la ciudad. Estos "modos de habitar" nos enfrentan a "ecuaciones" no lineales, sino complejas, en las que los actores constantemente comparan lo articulado y lo vivido (Williams, 1997). De esta manera, por un lado la centralidad y la accesibilidad del barrio tradicional tiene su contraparte en lo que se experimenta como una creciente inseguridad y la indiferencia en las interacciones de la vida cotidiana. Por otro lado, la deseada seguridad y tranquilidad que muchas personas buscaron en barrios cerrados alejados del centro son contrarrestadas por la alta movilidad cotidiana y la pérdida de relaciones sociales que impone este estilo de vida; y finalmente, las promesas de mejoras que ofrece la ciudad para los inmigrantes radicados en asentamientos periféricos, encuentra rápidamente sus límites en los distintos dispositivos (económicos, sociales, espaciales, simbólicos) que reproducen la desigualdad que afecta a los habitantes de los barrios pobres.

La diversidad (y desigualdad) de modos de habitar que coexisten en el espacio metropolitano tienen -como se desprende de las tres cartografías presentadas en este artículo- un rasgo común: la cualidad móvil del habitar, y por lo mismo la imposibilidad de circunscribir la experiencia del habitar dentro de los límites del espacio residencial. En este sentido, esta cualidad abre interrogantes relevantes para el análisis de las desigualdades urbanas en general, y específicamente permite problematizar las nociones habituales de segregación como un fenómeno exclusivamente residencial y la fragmentación como sinónimo de aislamiento y ausencia de interacción entre los fragmentos. En cambio, el análisis de las prácticas de movilidad cotidiana (los recorridos, sus bifurcaciones y sus entrelazamientos) muestra que la segregación y/o la fragmentación espacial no se reducen a un fenómeno residencial ni implican necesariamente ausencia 
de vínculos sino que refieren también -siguiendo la sutil sugerencia de Bayón y Saraví (2013)- a los modos en que se establecen y se experimentan los lazos sociales en la metrópoli contemporánea.

En este sentido, la investigación arrojó la existencia de un "doble movimiento" (Segura, 2018a). Por un lado, el análisis de las prácticas de movilidad cotidiana muestra que no hay fragmentos autónomos ni sujetos fijos, sino interconexión y movimiento. Por supuesto, las personas están en condiciones -y cuentan con medios y recursosdesiguales para moverse en la metrópoli, encontrándonos incluso ante situaciones en las cuales la movilidad reducida genera problemas de accesibilidad (Lucas, 2012), potenciando la desigualdad. Sin embargo, más allá de estos obstáculos, uno de los productos de esas movilidades es poner en contacto (o, al menos, aproximar) a personas que habitan en distintos lugares de ese espacio crecientemente fragmentado y que participan de circuitos socialmente segregados. Por otro lado, es precisamente en ese movimiento de aproximación e interconexión que se (re) producen la distancia y la separación propias de un universo socialmente fragmentado. De esta manera, además de conectar, las movilidades crean y re-crean fronteras y barreras (Caggiano y Segura, 2014). Las desigualdades urbanas, entonces, no solo remitirían al acceso diferencial a la ciudad sino también a la actualización de la distancia y la separación en las propias interacciones que se dan en el espacio urbano.

\section{Lógicas de circulación, interdependencias, género y curso de vida}

Además del análisis de los patrones de movilidad a escala municipal y de las relaciones entre tipos socio-urbanos y modos de vida, los relatos fueron analizados a nivel de unidad doméstica, con la pregunta por el género como dimensión transversal de la experiencia social en tanto producto y productor de las movilidades cotidianas en el espacio metropolitano (Chaves et al., 2017). A partir del análisis de los relatos identificamos tres tipos de movilidades cotidianas resultado de las cambiantes ecuaciones que se realizan entre trabajo, familia, casa y vida social, y para describirlos propusimos tres figuras con las que buscamos delinear modos típicos de recorrer y experimentar la ciudad.

La primera figura corresponde al oxímoron "encierro en movimiento" que busca condensar la experiencia cotidiana de personas, predominantemente mujeres, donde una disposición "tradicional" de los roles de género producto de acuerdos, interdependencias y asimetrías al interior de la unidad doméstica distribuye desigualmente tareas y actividades así como organiza andares diferenciales por la ciudad. En este sentido, el análisis de la movilidad cotidiana muestra que las tareas de reproducción del hogar no implican necesariamente la circunscripción al espacio de "la casa" y que la experiencia significada como "encierro" no supone necesariamente fijismo e inmovilidad sino que, además de ciertas inmovilidades, incluye una movilidad cotidiana de trayectos generalmente cortos y sobre todo definidos por el cuidado de otros: llevar los chicos a la escuela, realizar las compras para cocinar diariamente y realizar los trámites involucrados en el mantenimiento de la vivienda y de los hijos (salud, educación y/o documentación).

La segunda figura remite a la imagen de las "movilidades lineales" que conectan casa - trabajo - casa. Este tipo de movilidad es un modo clásico de experimentar la vida cotidiana en la ciudad, muy común en varones y mujeres insertas en el mercado laboral con trabajos de 8 a 12 horas diarias. En estos casos, cuando en una pareja ambos tienen movilidades lineales, la diferencia de género emerge no a través del tipo de movilidad o la posición laboral sino de las actividades que suman a esa esfera laboral, y las interdependencias que las tienen como eje o sostén. Por ejemplo, generalmente las mujeres que tienen movilidades cotidianas lineales de este tipo tienen a su cargo además las 
tareas domésticas y la coordinación de la movilidad de los hijos, debiendo conciliar los tiempos y las actividades del trabajo y de la casa. Más allá de estas desigualdades, la movilidad cotidiana se experimenta como un péndulo que conecta diariamente la casa y el trabajo.

Por último, la tercera figura de movilidad corresponde al "trabajo en movimiento", propia de personas cuyo trabajo presupone la movilidad constante (fletero, repartidor, docentes, policías) y/o que organizan su vida cotidiana como centro de las movilidades de otros (hijos, pareja). Estas movilidades se caracterizan, por un lado, por la sensación de agotamiento, el "estar a las corridas", siempre "de un lado a otro". Por otro lado, se trata de movilidades que incluyen un sinnúmero de arreglos domésticos así como grandes o pequeños desplazamientos casi constantes.

Estas tres "lógicas de circulación" (y sus combinaciones) nos permitieron caracterizar con mayor precisión las unidades domésticas y comparar con mayor profundidad los modos de vida predominantes en cada tipo socio-urbano. Se trata, en efecto, de lógicas de circulación que no solo pueden coexistir de manera articulada al interior de las unidades domésticas ${ }^{8}$ sino que también son transversales a los tipos socio-urbanos, habiendo identificado, por ejemplo, un alto predominio del "encierro en movimiento" entre mujeres de los tipos socio-urbanos villa/asentamiento y barrio cerrado, tendiendo en cambio a aumentar entre las mujeres las "movilidades lineales" y/o el "trabajo en movimiento" en barrios de clases medias y de clases medias-altas centrales.

Contra la imagen moderna del individuo libre móvil, lo que el análisis nos devuelve es la relevancia de las interdependencias cotidianas tanto al interior de la unidad doméstica como en relación a los medios de transporte, las redes sociales familiares y/o vecinales, las políticas públicas de educación, salud y cuidado, entre otras dimensiones de la vida metropolitana. Estas interdependencias pueden ser más o menos (a)simétricas y pueden generar u obturar el desarrollo personal. Asimismo, la temporalidad de la vida individual y familiar se tornó en un elemento clave para pensar las lógicas interdependientes de movilidad cotidiana (Chaves et al., 2017).

Las tres figuras de la movilidad propuestas permiten problematizar para el caso argentino, la distinción tajante propuesta por Duhau y Giglia (2008) para el caso mexicano entre espacio local o de proximidad (correspondientes a la vecindad o al barrio, con relaciones de intensidad variable) y espacio metropolitano en el cual "los sujetos dibujan sus relaciones en forma de telaraña, mucho menos densa, pero más amplia” (2008:22). En efecto, antes que una dualidad (o un salto) entre lo local y lo metropolitano, lo que estas figuras nos muestran son modos diversos de construir circuitos de acción cotidiana en la metrópoli que tienen formas, tiempos y escalas diversas.

\section{Reflexiones finales}

$\mathrm{Al}$ colocar el foco en las prácticas espacio-temporales de las y los habitantes y sus significaciones, el estudio de movilidades posibilita construir un "plano intermedio" (Magnani, 2002) para mirar y analizar el espacio metropolitano. No se trata ni del mapa panorámico de la ciudad, ni del individuo fijo en un punto de la ciudad, sino de personas "atravesando la espesura de la ciudad" (Jirón y Mansilla, 2013), realizando 
recorridos, armando circuitos, encontrando (y, a veces, superando) obstáculos, estableciendo relaciones y (re)produciendo diferencias (Segura, 2018a).

En este sentido, los "relatos de espacio" (De Certeau, 2000) producidos por medio de la interlocución con personas que residen en diferentes y desiguales "tipos sociourbanos" se mostraron como herramientas productivas para -metafóricamente- "seguir a los actores" en sus tránsitos cotidianos por el espacio metropolitano y conocer los modos (plurales, desiguales) en que experimentaban ese habitar cotidiano por medio del cual, simultáneamente, "hacen ciudad" (Agier, 2015). En este sentido, el espacio metropolitano se presenta no solo como condición (o contenedor) de la vida social, sino también como producto de la acción, como resultado de la práctica del lugar (De Certeau, 2000) y los relatos de espacio como herramienta para conocer esas prácticas.

Como señalaron hace ya un tiempo Sheller y Urry (2006) y Cresswell (2008), la movilidad no se reduce a movimiento sino que, además del hecho físico de trasladarse de un lugar al otro, la movilidad involucra también los sentidos otorgados al movimiento (real, imaginario, deseado) así como la práctica del movimiento experimentada y encarnada. Los relatos permiten acceder parcialmente a esas dimensiones y podrían complementarse con otras herramientas metodológicas que se vienen implementado en el abordaje de la movilidad: los "métodos móviles" que acompañan el movimiento de las personas y/o los objetos (Jirón, 2010; Merriman, 2013) y los diversos enfoques fenomenológicos de la movilidad que buscan acercarse a la experiencia encarnada del movimiento.

En definitiva, incluso con las propias limitaciones que toda propuesta metodológica tiene, el trabajo con los relatos permitió abordar tres cuestiones generales. Primero, el "contenido" de los relatos de espacio -los tiempos, los medios, los desplazamientos, etc.-, posibilitó seguir "metafóricamente" a las personas y comprender dinámicas clave de la movilidad cotidiana en la metrópoli. Segundo, la "forma" de los relatos de espacio -los modos de narrar los lugares y la movilidad a través de ellos así como las significaciones otorgadas a esas prácticas-, permitió identificar y abordar dimensiones y sentidos claves de la experiencia metropolitana. Y tercero, la escala de los relatos permitió abarcar distintas localidades del corredor sur de la RMBA intentado captar la heterogeneidad y desigualdad social de la metrópoli posibilitó, por comparación, caracterizar experiencias metropolitanas moduladas por el lugar de residencia, la clase, el género, la edad, las interdependencias que se producen entre los miembros de una unidad doméstica y las interacciones entre las y los habitantes y el estado y entre personas que "se mueven" por estos espacios.

\section{Agradecimiento: El presente artículo fue realizado en el marco del proyecto financiado por la Agencia Nacional de Promoción Científica y Tecnológica “La experiencia metropolitana del corredor sur de la RMBA: dominios urbanos, espacialidad y temporalidad en actores sociales con posiciones desiguales en la metrópoli" (PICT 2012-1270) dirigido por la Dra. Mariana Chaves.}




\section{Q Bibliografía}

" Agier, M. (2015). Do direito a cidade ao fazer-cidade. O antropólogo, a margen e o centro. Maná, 21 (3), 483-498.

"Arizaga, C. (2005). El mito de la comunidad en la ciudad mundializada. Estilos de vida y nuevas clases medias en urbanizaciones cerradas. Buenos Aires: El Cielo por Asalto.

" Auyeri, J. y Swistun, D. (2008). Inflamable. Estudio del sufrimiento ambiental. Buenos Aires: Paidós.

» Bayón, M. C. y Saraví, G. (2013). The Cultural Dimensions of Urban Fragmentation: Segregation, Sociability, and Inequality in Mexico City. Latin American Perspectives 40 (189), 35-52.

»Benjamin, W. (1986). Sobre el programa de la filosofía futura y otros ensayos. Barcelona: Planeta-Agostini.

"Benza, G. (2016). La estructura de clases argentina durante la década 20032013. En: G. Kessler (Comp.) La sociedad argentina hoy (pp. 111-140). Buenos Aires: Siglo XXI/Fundación OSDE.

"Bourdin, A. (2007). La metrópoli de los individuos. Puebla: Universidad Iberoamericana de Puebla.

»Büscher, M. y Veloso, L. (2018). Métodos móveis. Tempo Social, revista de sociologia da USP 30 (2), 133-151.

»Caggiano, S. y Segura, R. (2014). Migración, fronteras y desplazamientos en la ciudad. Dinámicas de la alteridad urbana en Buenos Aires. Revista de Estudios Sociales (48), 29-42.

»Caldeira, T. (2000). Cidade de Muros. San Pablo: Editora 34.

" Chaves, M. y Segura, R. (2017). Entrevista de vida cotidiana y movilidad. En A. Gutiérrez (Coord.) Manual sobre metodologías de estudio aplicables a la planificación y gestión del transporte y la movilidad. Recomendaciones sobre el uso de herramientas cuali-cuantitativas de base territorial (pp. 41-45). Buenos Aires: EUDEBA.

"Chaves, M. y Segura, R. (Eds.) (2015). Hacerse un lugar: circuitos y trayectorias juveniles en ámbitos urbanos. Buenos Aires: Biblos.

»Chaves, M.; Segura, R.; Cingolani, J.; y Hernández, C. (2018). Florencio Varela: modos de interacción social, segregaciones y nodos de intercambio. Ponencia presentada en el XXXI Congreso de la Asociación Latinoamericana de Sociología (ALAS), Montevideo.

" Chaves, M.; Segura, R.; Speroni, M.; y Cingolani, J. (2017). Interdependencias múltiples y asimetrías entre géneros en experiencias de movilidad cotidiana en el corredor sur de la Región Metropolitana de Buenos Aires (Argentina). Revista Transporte y Territorio. (16), 41-67.

"Ciccolela, P. (2011). Metrópolis latinoamericanas: más allá de la globalización. Quito, OLACHI.

"Cravino, C. (Org) (2008). Los mil barrios (in)formales. Aportes para la construcción de un observatorio del hábitat popular del Área Metropolitana de Buenos Aires. 
Los Polvorines: UNGS.

»Cresswell, T. (2008). Constellations of mobility. Institute of English Studies.

»De Certeau, M. (2000). La invención de lo cotidiano I. México: ITESO.

»Donzelot , J. (2004). La ville à trois vitesses: relégation, périurbanisation, gentrification. Esprit (303), 14-39.

"Duhau, E. y Giglia, A. (2008). Las reglas del desorden. Habitar la metrópoli. México: Siglo XXI.

» Ferraudi Curto, C. (2014). Ni punteros ni piqueteros: urbanización y política en una villa del conurbano. Buenos Aires: Gorla.

" Gorelik, A. (2011). Correspondencias. Arquitectura, ciudad, cultura. Buenos Aires: SCA/Nobuko.

» Grimson, A. (2009). Introducción: clasificaciones espaciales y territorialización de la política en Buenos Aires. En A. Grimson, C. Ferraudi Curto y R. Segura (Comp.). La vida política en los barrios populares de Buenos Aires (pp. 11-38). Buenos Aires: Prometeo.

" Grimson, A. y Segura, R. (2016). Space, Urban Borders and Political Imagination in Buenos Aires. Latin American \& Caribbean Ethnic Studies 11(1), 25-45.

» Gutiérrez, A. (Org.) (2017). Manual sobre metodologías de estudio aplicables a la planificación y gestión del transporte y la movilidad. Recomendaciones sobre el uso de herramientas cuali-cuantitativas de base territorial. Buenos Aires: EUDEBA.

»Gutiérrez, A. (2012). ¿Qué es la movilidad? Elementos para (re) construir las definiciones básicas del campo del transporte. Bitácora 21 (2), 61-74.

" Hannerz, U. (1986). La exploración de la ciudad. Hacia una antropología urbana. Buenos Aires: FCE.

»Ingold, T. (2011). Being Alive. Essays on Movement, Knowledge and Description. New York: Routledge.

» Janoschka, M. (2002). El nuevo modelo de la ciudad latinoamericana. Fragmentación y privatización. EURE, 28 (85), 11-20.

» Jirón, P. (2007). Implicancias de género en las experiencias de movilidad cotidiana urbana en Santiago de Chile. Revista Venezolana de Estudios de la Mujer 12 (29), 173-197.

» Jirón, P. (2009). Prácticas de Movilidad Cotidiana Urbana: Un Análisis para Revelar Desigualdades en la Ciudad. En M. Tironi y F. Pérez (Eds.) Espacios, Prácticas y Cultura Urbana (pp. 176-189). Santiago de Chile: ARQ Ediciones, Escuela de Arquitectura.

» Jirón, P. (2010). On becoming ‘la sombra/the shadow’. En: M. Büscher, J. Urry and K. Witchger (Eds), Mobile Methods (pp. 36-53). London: Routledge.

» Jirón, P. e Imilán, W. (2016). Observando juntos en movimiento: posibilidades, desafíos o encrucijadas de una etnografía colectiva. Alteridades 26(52), 51-64.

» Jirón, P. y Mansilla, P. (2013). Atravesando la espesura de la ciudad: vida cotidiana y barreras de accesibilidad de los habitantes de la periferia urbana de Santiago de Chile. Revista de Geografía Norte Grande (56), 53-74.

»Latour, B. (2008). Reensamblar lo social. Una introducción a la teoría del actorred. Buenos Aires: Manantial.

» Lucas, K. (2012). Transport and social exclusión: Where are we now? Transport 
Policy (20), 105-113.

» Magnani, J. (2002). De perto e de dentro: notas para uma etnografía urbana. Revista brasileira de ciencias sociales 17(49), 11-29.

» Marcus, G. (2001). Etnografía en/del sistema mundo. El surgimiento de la etnografía multilocal. Alteridades 11(22), 111-127.

» Merriman, P. (2013). Rethinking mobile methods. Mobilities 9(2), 167-187.

»Mongin, O. (2006) La condición urbana. La ciudad a la hora de la mundialización. Buenos Aires: Paidós.

» Piglia, R. (2014). Modos de narrar. En: Antología personal (pp. 241-251). Buenos Aires: FCE.

»Pinedo, J. (2018). Urdimbres y tramas. Transformaciones de la acción colectiva popular en el sur del Gran Buenos Aires" (1974-1989), Tesis doctoral en Ciencias Sociales, Universidad Nacional de General Sarmiento.

»Prévot-Schapira, M. F. (2001). Fragmentación espacial y social: conceptos y realidades. Perfiles Latinoamericanos (19), 33-56.

» Segura, R. (2012). Elementos para una crítica de la noción de segregación residencial socio-económica: desigualdades, desplazamientos e interacciones en la periferia de La Plata. Quid 16 (2), 106-132.

»Segura, R. (2015). Vivir afuera. Antropología de la experiencia urbana. Buenos Aires: UNSAM Edita.

"Segura, R. (2018a). La ciudad de los senderos que se bifurcan (y se entrelazan): centralidades conflictivas y circuitos segregados en una ciudad intermedia de la Argentina. Universitas Humanística (85), 155-181.

»Segura, R. (2018b). Ways of Dwelling: Location, Daily Mobility and Segregated Circuits in the Urban Experience of the Modern Landscape of La Plata. En B. Freire-Medeiros and J. O'Donnell (Eds.) Urban Latin America: Images, Words, Flows and the Built Environment (pp. 156-172). New York: Routledge.

»Segura, R. y Chaves, M. (2019). Modos de habitar: localización, tipo residencial y movilidad cotidiana en el Gran La Plata. En M. Di Virgilio y M. Perelman (Eds.) Disputas por el espacio urbano. Desigualdades persistentes y territorialidades emergentes (pp. 193-222). Buenos Aires: Biblos.

»Sheller, M. and Urry, J. (2006). The new mobilities paradigm. Environment and Planning (38), 207-226.

"Svampa, M. (2004). La brecha urbana. Buenos Aires: Capital Intelectual.

»Thuillier, G. (2005). El impacto socio-espacial de las urbanizaciones cerradas: el caso de la Región Metropolitana de Buenos Aires. EURE 31(93), 5-20.

»Urry, J. (2002). Mobility and Proximity. Sociology 36(2), 255-274.

"Williams, R. (1997). Marxismo y Literatura. Península: Barcelona.

"Williams, R. (2000) Experiencia. En Palabras clave (pp. 137-140). Buenos Aires: Nueva Visión.

» Zunino Singh, D.; Giucci, G. y Jirón, P. (2018). Introducción. En: Zunino Singh, D.; Giucci, G. y Jirón, P. (Eds.) Términos clave para los estudios de movilidad en América Latina (pp. 13-21). Buenos Aires: Biblos. 


\section{Ramiro Segura / segura.ramiro@gmail.com}

Licenciado en Antropología (UNLP), Doctor en Ciencias Sociales (UNGS-IDES) y Postdoctorado en FU Berlín. Investigador del CONICET. Profesor en la Universidad Nacional de La Plata y en la Universidad Nacional de San Martín. Publicó artículos en revistas de la especialidad sobre desigualdades urbanas, segregación residencial y movilidades urbanas.

\section{Mariana Chaves / chavesmarian@gmail.com}

Licenciada en Antropología (UNLP), Doctora en Ciencias Naturales con orientación en Antropología (UNLP). Investigadora del CONICET. Profesor en la Universidad Nacional de La Plata. Publicó artículos en revistas de la especialidad sobre juventudes, desigualdades y cuestiones urbanas. 